\title{
Effect of stand and tree attributes on growth and wood quality characteristics from a spacing trial with Populus xiaohei
}

\author{
Ze-Hui JiAng, Xiao-Qing WAnG*, Ben-Hua FEI, Hai-Qing REN, Xing-E LIU \\ Research Institute of Wood Industry, Chinese Academy of Forestry, Beijing 100091, China
}

(Received 19 December 2006; accepted 12 April 2007)

\begin{abstract}
The effect of stand density (1000 stems/ha, 500 stems/ha and 250 stems/ha) on tree growth and wood quality characteristics was studied in a 27-year-old plantation species of Populus xiaohei in China. Results indicated that stand density had significant effects on tree radial growth and crown size, and the lowest stand density produced trees with the largest stem taper. In terms of wood quality characteristics, there was no significant effect of stand density on either wood basic density or fiber length. However, significant differences were found between different stand densities for wood mechanical properties. A positive relationship between modulus of elasticity, compression strength and stand density was observed, while the highest modulus of rupture was recorded at a moderate density of $500 \mathrm{stems} / \mathrm{ha}$. Stand density was responsible for highly significant effects on both juvenile wood and wet heartwood basal areas in individual trees, and there was an obvious tendency towards increasing juvenile wood and wet heartwood basal areas with decreasing stand density. In addition, the relationships between wood quality characteristics and tree and stand characteristics were also examined. Some wood quality characteristics, namely mechanical properties and juvenile wood and wet heartwood basal areas, were quantified successfully in relation to selected tree characteristics using a regression approach with various degrees of goodness of fit. Based on comprehensive consideration of various factors, such as wood quality, tree growth, and establishment cost, results from this study suggest that a density of 500 stems/ha is optimum for wood production.
\end{abstract}

stand density / wood quality / tree characteristics / wet heartwood / Populus xiaohei

Résumé - Effets de la densité de plantation sur la croissance et la qualité des bois dans un dispositif d'espacement de Populus xiaohei. Ce travail analyse les effets de la densité de plantation (1000 tiges/ha, 500 tiges/ha and 250 tiges/ha) sur la croissance et la qualité du bois dans une plantation chinoise de Populus xiaohei âgée de 27 ans. Les résultats montrent (i) que la densité de plantation affecte significativement la croissance radiale et la dimension des houppiers et (ii) que la densité la plus faible conduit à des arbres ayant le défilement le plus important. Par contre, il n'y a aucun effet de la densité de plantation sur la densité du bois ou sur la longueur des fibres. Cependant, il existe des différences significatives entre traitements pour les propriétés mécaniques. Nous avons observé une corrélation positive entre le module d'élasticité, la résistance en compression et la densité de plantation tandis que le module de rupture le plus élevé a été obtenu pour la densité de plantation intermédiaire de 500 tiges/ha. La densité de plantation est responsable des effets les plus significatifs sur les surfaces terrières de bois juvénile et de cour humide qui augmentent lorsque la densité de plantation diminue. Nous avons également analysé les relations entre la qualité des bois et les caractéristiques des arbres et des peuplements. Certaines propriétés du bois comme les propriétés mécaniques et les surfaces terrières de bois juvénile et de cœur humide ont été quantifiées avec succès par l'utilisation de régressions multiples. À partir de ces résultats il a été possible de prendre en compte différents facteurs tels que la qualité des bois, la croissance et le coût d'installation des différentes densités de plantation et de montrer que la densité de plantation de 500 tiges/ha est optimale pour la production de bois.

densité de plantation / qualité des bois / caractéristiques dendrométriques des arbres / cour humide / Populus xiaohei

\section{INTRODUCTION}

With the rapid development of the Chinese economy and the growing human population, the Chinese forest industry is faced with great pressure to meet increasing demands for wood products, which is especially true since the National Natural Forest Protection Program was implemented by the central government in 1998 [10]. As an alternative, plantation forests are playing critical roles in meeting the nation's wood demand and preserving the environment, and a variety of silvicultural practices are being designed and applied to improve the productivity and wood quality of the forest stand in the context of intensive forest management $[11,18]$.

\footnotetext{
*Corresponding author: wxqlily@yahoo.com.cn
}

Stand density is one of the most important silvicultural factors used to control tree growth and wood quality by altering growing conditions in utilization of nutrients, water and sunlight, which will eventually affect the characteristics of the wood produced $[32,36]$. Traditionally, stand density control methods aimed at maximizing tree growth and wood volume production, while wood quality was a factor only discussed in qualitative terms. However, for effective forest management a quantitative assessment of the relationship between growth and wood quality is needed. Although a wide variety of studies have been carried out to quantify the effect of stand density (spacing) on wood quality characteristics such as wood density [22], fiber properties [26], wood strength [20], and juvenile wood content [28], a generalization of the impact of 
Table I. Mean statistics of tree growth attributes for the 36 sample trees from three stand densities of Populus xiaohei.

\begin{tabular}{|c|c|c|c|c|c|c|c|c|}
\hline SD (stems/ha) & Number of sample trees & $\mathrm{DBH}(\mathrm{cm})$ & $\mathrm{H}(\mathrm{m})$ & $\mathrm{CW}(\mathrm{m})$ & CL (m) & $\mathrm{CH}(\mathrm{m})$ & $\mathrm{ST}(\mathrm{cm} / \mathrm{m})$ & $\mathrm{HD}(\mathrm{m} / \mathrm{cm})$ \\
\hline 1000 & 14 & $19.53(2.79) \mathrm{C}^{*}$ & $18.07(1.39) \mathrm{A}$ & $3.20(1.33) \mathrm{B}$ & $6.80(1.32) \mathrm{B}$ & $11.27(0.29) \mathrm{A}$ & $0.73(0.11) \mathrm{B}$ & $0.93(0.07) \mathrm{A}$ \\
\hline 500 & 13 & $22.60(2.24) \mathrm{B}$ & $17.75(0.48) \mathrm{A}$ & $3.63(0.87) \mathrm{B}$ & $6.88(0.89) \mathrm{B}$ & $10.87(0.41) \mathrm{B}$ & $0.78(0.13) \mathrm{B}$ & $0.79(0.06) \mathrm{B}$ \\
\hline 250 & 9 & $26.87(1.36) \mathrm{A}$ & $17.74(0.42) \mathrm{A}$ & $5.14(1.06) \mathrm{A}$ & $8.28(0.41) \mathrm{A}$ & $9.47(0.01) \mathrm{C}$ & $0.98(0.12) \mathrm{A}$ & $0.66(0.02) \mathrm{C}$ \\
\hline
\end{tabular}

$\mathrm{SD}$, stand density; DBH, diameter at breast height; ST, stem taper; H, total tree height; CL, crown length; CW, crown width; HD, ratio of total tree height to $\mathrm{DBH} ; \mathrm{CH}$, tree height below the live crown; values in parentheses represent standard deviations.

* The same letter in the same column indicates that the differences between these stand densities are not significant at $P<0.05$ as determined by SNK test.

stand density on wood quality has not yet be established due to the fact that the response of wood quality to stand density is specific for individual woody species and is also modified by environmental factors $[28,36]$.

Poplars are widely planted in China for reforestation and commercial wood products, accounting for approximately $20 \%$ of the national plantation with an estimated area of 6.67 million ha [16]. In particular, Populus xiaohei is one of the most important poplar species prevailing in the provinces of Heilongjiang, Jilin and Shanxi of northern China, and is highly valued for pulpwood and lumber production. However, the occurrence of wet heartwood and high juvenile wood content is frequent in this fast-growing poplar species, which tends to cause problems for wood utilization. Furthermore, as yet no research has been carried out into its basic wood characteristics, and the relationship between silvicultural practice and wood quality has scarcely been quantified [23]. To provide valuable information for forest management, it is necessary to clarify how wood quality characteristics respond to different stand densities in this species.

The specific objectives of this study were two-fold. First, we intended to quantify the effects of stand density on tree growth and wood quality in mature plantations of Populus xiaohei. A better understanding of the effects of stand density on growth and wood quality will be helpful in making sound silvicultural strategies to produce high-quality wood while not reducing wood volume growth. Secondly, we aimed to develop models to predict wood quality characteristics based on tree and stand characteristics. Modeling wood quality in relation to tree characteristics will allow the evaluation of wood quality in standing trees directly from inventory data, since tree characteristics (e.g. diameter at breast height, tree height) are routinely recorded in forest inventories.

\section{MATERIALS AND METHODS}

\subsection{Study site and sample selection}

The study site was situated in a state-owned forest station (latitude $39^{\circ} 18^{\prime} \mathrm{N}$, longitude $112^{\circ} 33^{\prime} \mathrm{E}, 1060 \sim 1100 \mathrm{~m}$ above sea level) in Shuozhou, Shanxi province. The plantation was established in April, 1977, and was dominated by Populus xiaohei T.S. Hwang \& Liang, with an area of approximately 21.6 ha on a flat terrain. The average annual air temperature of this area is $7{ }^{\circ} \mathrm{C}$, and mean annual precipitation is $400 \mathrm{~mm}$. Soil texture in the surface layer is sandy loam with an organic matter content of $0.4 \%$.
There are a total of nine stand densities present in this plantation. Based on preliminary studies on growing conditions of different stands [22], three stands with densities of $1000(2 \mathrm{~m} \times 5 \mathrm{~m}), 500(4 \mathrm{~m}$ $\times 5 \mathrm{~m})$ and $250(4 \mathrm{~m} \times 10 \mathrm{~m}) \mathrm{stems} /$ ha were selected. From each of these stands, 14, 13 and 9 sample trees, respectively, were selected to cover different $\mathrm{DBH}$ classes at 2-cm intervals (e.g., 16, 18, 20, $\ldots \mathrm{cm}$ ), for a total of 36 trees. For each sample tree, the following tree characteristics were measured in the field: outside bark diameter at breast height $(\mathrm{DBH})$, total tree height $(\mathrm{H})$, crown width $(\mathrm{CW})$, crown length (CL), and tree height below the live crown. The projected on-ground crown radii from four directions (east, west, north, and south) were measured to determine crown width. Based on the above measurements, average stem taper (ST) and height-to-diameter (HD) ratio, which are both important stem quality parameters, were calculated. Stem taper was defined as the change in stem radius divided by the length of the bole between two radial measurements [33]. In this study, ST was calculated based on the middle tree height. The field data for the 36 sample trees are presented in Table I.

\subsection{Specimen preparation and testing}

In this study, the following important wood characteristics were selected for wood quality assessment in Populus xiaohei: basic density, fiber length, modulus of elasticity in static bending (MOE), modulus of rupture in static bending (MOR), compression strength parallel to the grain, juvenile wood basal area (JWA) and wet heartwood basal area (HWA) at breast height.

From each sample tree, a 5-mm diameter increment core was extracted from the bole at breast height for basic density testing. In addition, a 10-cm thick disk was cut at breast height, which was further separated into two sub-disks: one for anatomical property analysis, i.e. fiber length, and the other for measuring JWA and HWA. A 2 mlong log from a stem height of 1.3 to $3.3 \mathrm{~m}$ provided material for the determination of mechanical properties (i.e., MOE, MOR, compression strength parallel to the grain). From this, small clear samples were cut in accordance with Chinese National Standards for mechanical property determination [21]. For determination of physical and mechanical properties, the specimens should be air-conditioned at a temperature of $20 \pm 3{ }^{\circ} \mathrm{C}$ and relative humidity of $65 \pm 2 \%$ to achieve a constant moisture content before being subjected to testing.

\subsubsection{Basic density}

Basic density was calculated based on the oven-dry weight/green volume. The green volume was measured by the conventional water displacement method, and the oven-dry weight was determined using 
Table II. Mean statistics of wood quality characteristics for the 36 sample trees from three stand densities of Populus xiaohei.

\begin{tabular}{|c|c|c|c|c|c|c|c|c|c|c|}
\hline SD (stems/ha) & Number of sample trees & $\mathrm{BD}\left(\mathrm{g} / \mathrm{cm}^{3}\right)$ & $\operatorname{MOE}(\mathrm{MPa})$ & $\operatorname{MOR}(\mathrm{MPa})$ & $\mathrm{CS}(\mathrm{MPa})$ & $\mathrm{FL}(\mathrm{mm})$ & JWA $\left(\mathrm{cm}^{2}\right)$ & HWA $\left(\mathrm{cm}^{2}\right)$ & JWP (\%) & $\operatorname{HWP}(\%)$ \\
\hline 1000 & 14 & $0.331 \mathrm{~A}^{*}$ & $10941 \mathrm{~A}$ & $71.9 \mathrm{AB}$ & $40.2 \mathrm{~A}$ & $1.03 \mathrm{~A}$ & $178 \mathrm{C}$ & $141 \mathrm{C}$ & $77.4 \mathrm{~B}$ & $60.0 \mathrm{~B}$ \\
\hline 500 & 13 & $0.337 \mathrm{~A}$ & $10538 \mathrm{~A}$ & $74.1 \mathrm{~A}$ & $39.9 \mathrm{~A}$ & $1.05 \mathrm{~A}$ & $244 \mathrm{~B}$ & $198 \mathrm{~B}$ & $73.9 \mathrm{~B}$ & $60.7 \mathrm{~B}$ \\
\hline 250 & 9 & $0.328 \mathrm{~A}$ & $9738 \mathrm{~B}$ & $70.2 \mathrm{~B}$ & $36.7 \mathrm{~B}$ & $1.07 \mathrm{~A}$ & $368 \mathrm{~A}$ & $303 \mathrm{~A}$ & $82.8 \mathrm{~A}$ & $68.1 \mathrm{~A}$ \\
\hline
\end{tabular}

$\mathrm{BD}$, basic density; MOE, modulus of elasticity in static bending; MOR, modulus of rupture in static bending; CS, compression strength parallel to the grain; FL, fiber length; JWA, basal area of juvenile wood at breast height; HWA, basal area of wet heartwood at breast height; JWP, the proportion of juvenile wood basal area at breast height; HWP, the proportion of wet heartwood basal area at breast height.

* The same letter in the same column indicates that the differences between these stand densities are not significant at $P<0.05$ as determined by SNK test.

an electronic balance. Then, the basic density was obtained using the formula below:

$$
\rho=\frac{m}{v}
$$

Where $\rho$ is basic density $\left(\mathrm{g} / \mathrm{cm}^{3}\right), m$ is oven-dry weight $(\mathrm{g})$, and $v$ is green volume $\left(\mathrm{cm}^{3}\right)$.

\subsubsection{Fiber length}

For measurements of fiber length, specimens resembling matchsticks were prudently cut from the central strip of each disk with a sharp knife, and were then macerated with glacial acetic acid: $20 \%$ hydrogen peroxide $1: 1$ at $60{ }^{\circ} \mathrm{C}$ for $48 \mathrm{~h}$. Macerated specimens were thoroughly washed with clean water. The fiber length was measured using a projection microscope, under a magnification of $100 \times$. Fifty fibers were measured for each growth ring, and the mean value was used as the fiber length for each growth ring. Consequently, the fiber length of each sample tree was represented by the mean of all growth ring values.

\subsubsection{JWA and $H W A$}

Prior to measurement, juvenile wood and wet heartwood must be demarcated from the whole disk, respectively. Demarcation between juvenile and mature wood was carried out using the method described by Yang [28]. Wet heartwood was distinguished based on its inherent characteristics such as its deep-colored appearance. After a demarcation line was marked on each disk, an image analysis software, i.e., SigmaScan (Systat Software, 5.0), was employed to measure and calculate the JWA and HWA for all disks from their digital photographs.

\subsubsection{Mechanical properties}

Tests to determine MOE, MOR and compression strength were carried out using a universal testing machine (TCM-5000C, Keiaisha NMB Co. Tokyo, Japan). The sample dimension for MOE and MOR was $20 \mathrm{~mm}(\mathrm{R}) \times 20 \mathrm{~mm}(\mathrm{~T}) \times 300 \mathrm{~mm}(\mathrm{~L})$, and was $20 \mathrm{~mm}(\mathrm{R})$ $\times 20 \mathrm{~mm}(\mathrm{~T}) \times 30 \mathrm{~mm}(\mathrm{~L})$ for compression strength. Values were calculated using the following formulae. Each test was conducted on at least 30 small clear specimens for each sample tree according to national standards [21].

$$
\text { MOR }=\frac{3 P_{\max } L}{2 b h^{2}}
$$

Where MOR is measured in $\mathrm{MP}_{\mathrm{a}}, P_{\max }$ is the destructive load (N), $L$ is the span $(\mathrm{mm}), b$ is the width of the sample $(\mathrm{mm})$, and $h$ is the depth of the sample $(\mathrm{mm})$.

$$
\text { MOE }=\frac{23 P L^{3}}{108 b h^{3} f}
$$

Where MOE is measured in $\mathrm{MP}_{\mathrm{a}}, P$ is the load $(\mathrm{N}), L$ is the span $(\mathrm{mm}), f$ is the deflection $(\mathrm{mm}), b$ is the width of the sample $(\mathrm{mm})$, and $h$ is the depth of the sample (mm).

$$
C S=\frac{P_{\max }}{b t}
$$

Where CS is compression strength parallel to the grain measured in $\mathrm{MP}_{\mathrm{a}}, P_{\max }$ is the destructive load $(\mathrm{N}), b$ is the width of the sample $(\mathrm{mm})$, and $t$ is the thickness of the sample (mm).

The summary statistics of the wood quality parameters of all sample trees are presented in Table II.

\subsection{Statistical analysis}

Statistical analysis was conducted using SAS programs (SAS Institute, Inc. 8.0). One-way analysis of variance (ANOVA) was performed to evaluate the impact of stand density on wood quality characteristics. A multiple comparison process with Student-NewmanKeuls (SNK) was also carried out to show the differences between the stand densities. Correlation coefficients between tree/stand characteristics and wood quality parameters were also calculated to explore their relationships.

Furthermore, multiple regression equations were established to predict wood quality using tree and stand characteristics as predictor variables. To develop regression models, it is important to select proper variables, model forms, and to use good parameter estimation procedures and model evaluation techniques [34]. To achieve better results, transformations of the dependent and independent variables were also attempted. A stepwise procedure was used to determine the best predictor variables for the regression models. In this study, the significance level to enter and stay was set to the default value of 0.15 . The variance inflation factor (VIF) was applied to detect multicollinearity of the predictor variables. The established models were evaluated based on the coefficient of determination $\left(R^{2}\right)$, the root mean square error (RMSE), and significance. In addition, the predicted residual sums of squares (PRESS) was also included as it can be used to examine the predictive abilities of candidate regression models, which is ideal for cases where sample sizes are small. 


\section{RESULTS}

\subsection{Effects of stand density on growth and wood quality characteristics}

The tree growth characteristics from different stand densities are listed in Table I. There was a significant effect of stand density on $\mathrm{DBH}$, while differences in tree height were not found. A significant effect of stand density on crown size (CW and CL) was also observed, and the lowest stand density produced the largest crowns. There were also significant stand density effects for both stem quality parameters (ST and HD).

The basic density value ranged from $0.331 \mathrm{~g} / \mathrm{cm}^{3}$ to $0.337 \mathrm{~g} / \mathrm{cm}^{3}$, depending on the stand density (Tab. II). The ANOVA results clearly indicated that there was no significant difference in basic density between these stand densities. Similarly, although a tendency of decreasing fiber length with increasing stand density was noticed, the ANOVA results showed there was no significant effect of stand density on fiber length.

By contrast, there were significant effects of stand density on MOE, MOR and compression strength. Specifically, an SNK test (Tab. II) indicated that there was a significant difference in MOE between 250 stems/ha and the two higher densities, while a difference was not found between the two higher densities. In terms of MOR, a significant difference was found only between the two lower densities. Similarly to MOE, the difference in compression strength was found only between 250 stems/ha and the two higher densities. Tendencies of positive relationships between stand density and both MOE and compression strength were observed, whereas the highest MOR was recorded at the moderate density of 500 stems/ha.

There were significant differences in HWAs between stand densities (Tab. II). An obviously negative relationship between the HWA and stand density was found. Correspondingly, the wet heartwood proportion (HWP) increased remarkably from $60.0 \%$ at the highest stand density to $68.1 \%$ at the lowest. Both ANOVA results and SNK testing showed that the difference was highly significant, and was found only between the two higher densities and the lowest density.

As seen with the HWA, an obvious tendency of increasing JWA with decreasing stand density was observed, and there was significant difference in JWA between these stand densities. Concerning the juvenile wood proportion (JWP), the significant difference was found only between the lowest density and the two higher densities (Tab. II).

\subsection{Relationships between tree characteristics and wood quality parameters}

The correlation coefficients between tree characteristics and wood quality parameters in Populus xiaohei were calculated (Tab. III). Generally, the tree characteristics showed various degrees of correlation with wood quality parameters. Basic density was independent of any tree characteristic, and fiber length was positively related to most tree characteristics, especially to $\mathrm{DBH}$ and $\mathrm{CW}$. By contrast, there were significant negative relationships between mechanical properties and most tree characteristics. Both JWA and HWA were found to be highly correlated with tree characteristics (with the exception of $\mathrm{H}$ ), especially with DBH and HD. However, relatively weak correlations between the proportions of juvenile wood and wet heartwood and tree characteristics were observed.
Table III. Correlation coefficients between tree characteristics and wood quality parameters for the 36 sample trees of Populus xiaohei.

\begin{tabular}{lcccccc}
\hline Variables & DBH & H & CW & CL & ST & HD \\
\hline BD & $-0.015^{*}$ & -0.077 & -0.099 & -0.079 & -0.102 & -0.053 \\
MOE & -0.624 & -0.256 & -0.510 & -0.557 & -0.387 & 0.601 \\
MOR & -0.396 & -0.344 & -0.330 & -0.530 & -0.484 & 0.302 \\
CS & -0.729 & -0.217 & -0.590 & -0.655 & -0.628 & 0.700 \\
FL & 0.440 & 0.237 & 0.446 & 0.404 & 0.201 & -0.422 \\
JWA & 0.939 & 0.261 & 0.778 & 0.787 & 0.695 & -0.923 \\
JWP & 0.175 & -0.242 & 0.260 & 0.104 & 0.363 & -0.167 \\
HWA & 0.904 & 0.269 & 0.757 & 0.756 & 0.579 & -0.892 \\
HWP & 0.305 & 0.081 & 0.329 & 0.245 & -0.083 & -0.305 \\
\hline
\end{tabular}

$* \mathrm{df}=35, \mathrm{t}_{0.05}=0.324, \mathrm{t}_{0.01}=0.418, \mathrm{t}_{0.001}=0.519$.

$\mathrm{BD}$, basic density; MOE, modulus of elasticity in static bending; MOR, modulus of rupture in static bending; CS, compression strength parallel to the grain; FL, fiber length; JWA, basal area of juvenile wood at breast height; HWA, basal area of wet heartwood at breast height; JWP, the proportion of juvenile wood basal area at breast height; HWP, the proportion of wet heartwood basal area at breast height; $\mathrm{DBH}$, diameter at breast height; ST, stem taper; $\mathrm{H}$, total tree height; $\mathrm{CL}$, crown length; CW, crown width; HD, ratio of total tree height to $\mathrm{DBH}$.

\subsection{Modeling wood quality parameters in relation to tree characteristics}

The best models determined by the stepwise procedure are listed in Table IV. Modulus of elasticity was best predicted by the reciprocal of HD and DBH, with a $R^{2}$ value of 0.48 (model 1$)$. An examination of the cumulative $R_{\mathrm{p}}^{2}$ showed that the reciprocal of HD was the best explanatory variable ( $42 \%$ of total variation), followed by DBH. Regarding the MOR equation, MOE was introduced in addition to the reciprocal of ST and SD, and the total amount of variation explained was somewhat higher than that of the MOE model $\left(R^{2}=0.53\right)$. The reciprocal of ST was the best predictor variable (29\% of total variation), followed by MOE and SD. By contrast, model 3 could explain approximately $66 \%$ of the total variation in compression strength using MOE and ST as predictor variables. Particularly, MOE alone could explain much of the variation (49\%), followed by ST, as indicated by examination of the cumulative $R_{\mathrm{p}}^{2}$.

Juvenile wood basal area was best predicted by DBH and SD (model 4), and most of the variation in JWA was explained by the tree characteristics included in this power function model $\left(R^{2}=0.93\right)$. Particularly, DBH alone explained most of the variation (92\%), and therefore SD accounted for little variation in JWA. For the power function model of HWA, the total amount of variation explained was comparable with that of the JWA model $\left(R^{2}=0.89\right)$, and DBH, likewise, explained most of the variation in HWA $(85 \%)$.

Unfortunately, a model for basic density could not be established, and none of the tree characteristics was selected by the stepwise procedure. Although some tree characteristics were selected for the models of fiber length, JWP and HWP, only a small amount of variation in these wood quality characteristics was explained by these models. This indicates that these models are inadequate in describing the relationships of fiber length, JWP and HWP with tree characteristics. 
Table IV. The selected models determined by the stepwise procedure to describe wood quality characteristics in relation to tree characteristics in Populus xiaohei.

\begin{tabular}{|c|c|c|c|c|c|c|c|c|c|c|}
\hline \multirow{2}{*}{ Model } & \multirow{2}{*}{ Dependent variables } & \multirow{2}{*}{ Independent variables } & \multicolumn{3}{|c|}{ Parameter estimation } & \multicolumn{2}{|c|}{ Coefficient of determination } & \multirow{2}{*}{ RMSE } & \multirow{2}{*}{ PRESS } & \multirow{2}{*}{$P$} \\
\hline & & & $\overline{\text { Regression coefficient (SE) }}$ & $P$ & VIF & $R^{2}$ & $R_{\mathrm{p}}^{2}$ & & & \\
\hline \multirow{3}{*}{1} & \multirow{3}{*}{ MOE } & Intercept & $13.046(0.570)$ & $<0.0001$ & 0 & & & & & \\
\hline & & $1 / \mathrm{HD}$ & $-5.404(1.877)$ & 0.0076 & 18.0270 .4832 & & 0.4232 & 0.467 & 7.502 & $<0.0001$ \\
\hline & & $\mathrm{DBH}$ & $0.181(0.100)$ & 0.0823 & 18.027 & & 0.4832 & & & \\
\hline \multirow{4}{*}{2} & \multirow{4}{*}{ MOR } & Intercept & $44.570(6.277)$ & $<0.0001$ & 0 & \multirow{4}{*}{0.5257} & & \multirow{4}{*}{2.343} & \multirow{4}{*}{225.259} & \multirow{4}{*}{$<0.0001$} \\
\hline & & $1 / \mathrm{ST}$ & $7.420(1.678)$ & 0.0001 & 1.262 & & 0.2870 & & & \\
\hline & & $\mathrm{SD}$ & $-0.005(0.002)$ & 0.0018 & 1.490 & & 0.3686 & & & \\
\hline & & MOE & $2.049(0.640)$ & 0.0031 & 1.343 & & 0.5257 & & & \\
\hline \multirow{3}{*}{3} & \multirow{3}{*}{$\mathrm{CS}$} & Intercept & $29.338(3.392)$ & $<0.0001$ & 0 & \multirow{3}{*}{0.6575} & & \multirow{3}{*}{1.080} & \multirow{3}{*}{44.937} & \multirow{3}{*}{$<0.0001$} \\
\hline & & MOE & $1.330(0.274)$ & $<0.0001$ & 1.160 & & 0.4941 & & & \\
\hline & & $\mathrm{ST}$ & $-5.052(1.293)$ & 0.0005 & 1.160 & & 0.6575 & & & \\
\hline \multirow{3}{*}{4} & \multirow{3}{*}{ JWA } & Intercept & $2.322(2.011)$ & 0.2367 & 0 & \multirow{3}{*}{0.9333} & & \multirow{3}{*}{25.248} & \multirow{3}{*}{24857} & \multirow{3}{*}{$<0.0001$} \\
\hline & & $\mathrm{DBH}$ & $1.741(0.147)$ & $<0.0001$ & 2.349 & & 0.9184 & & & \\
\hline & & $\mathrm{SD}$ & $-0.124(0.046)$ & 0.0105 & 2.349 & & 0.9333 & & & \\
\hline \multirow{4}{*}{5} & & Intercept & $0.674(2.805)$ & 0.7048 & 0 & & & & & \\
\hline & HWA & DBH & $2.139(0.225)$ & $<0.0001$ & 2.596 & 08945 & 0.8509 & 29949 & 35591 & $<00001$ \\
\hline & & ST & $-0.477(0.156)$ & 0.0045 & 1.628 & & 0.8724 & & & $<0.0001$ \\
\hline & & $\mathrm{SD}$ & $-0.176(0.068)$ & 0.0144 & 2.468 & & 0.8945 & & & \\
\hline 6 & Basic density & NA & NA & NA & NA & NA & NA & NA & NA & NA \\
\hline 7 & Fib & Intercept & $978.557(23.821)$ & $<0.0001$ & 0 & 01080 & & 16441 & 81050 & 00064 \\
\hline 7 & Fiber length & $\mathrm{CW}$ & $17.039(5.865)$ & 0.0064 & 1.000 & 0.1989 & 0.1989 & 46.441 & 81959 & 0.0064 \\
\hline & & Intercept & $121.780(18.079)$ & $<0.0001$ & 0 & & & & & \\
\hline 8 & JWP & $\mathrm{CW}$ & $2.084(0.748)$ & 0.0087 & 1.285 & 0.2380 & 0.0674 & 5.222 & 1045 & 0.0113 \\
\hline & & $\mathrm{H}$ & $-2.925(1.076)$ & 0.0104 & 1.285 & & 0.2380 & & & \\
\hline & & Intercept & 83.027 (9.969) & $<0.0001$ & 0 & & & & & \\
\hline 9 & HWP & $\mathrm{CW}$ & $2.829(1.168)$ & 0.0213 & 1.618 & 03203 & 0.1083 & 7272 & 2071 & 00058 \\
\hline & HWP & ST & $-30.780(10.516)$ & 0.0063 & 1.728 & 0.3203 & 0.2188 & 7.272 & 2071 & 0.0058 \\
\hline & & SD & $-0.0107(0.0049)$ & 0.0363 & 1.560 & & 0.3203 & & & \\
\hline
\end{tabular}

MOE, modulus of elasticity in static bending; MOR, modulus of rupture in static bending; CS, compression strength parallel to the grain; JWA, basal area of juvenile wood at breast height; HWA, basal area of wet heartwood at breast height; SD, stand density; DBH, diameter at breast height; ST, stem taper; H, total tree height; CW, crown width; HD, ratio of total tree height to DBH; JWP, the proportion of juvenile wood basal area at breast height; HWP, the proportion of wet heartwood basal area at breast height.

Model 4 and model 5 take the following forms, respectively: $J W A=a_{0} D B H^{a 1} S D^{a 2} ; H W A=a_{0} D B H^{a 1} S T^{a 2} S D^{a 3}$; where, $a_{0} \sim a_{3}$ are the corresponding regression coefficients. $R_{\mathrm{p}}^{2}$ is the cumulative coefficient of determination for the variable and any variables prior to it in the model. NA means not available.

\section{DISCUSSION}

\subsection{Effects of stand density on growth and wood quality characteristics}

It has been recognized that stand density has a significant impact on tree growth, stand productivity and the quality of the wood produced [36]. The present study clearly demonstrated that stand density showed various degrees of impact on tree growth and wood quality characteristics in Populus xiaohei. Specifically, trees grew faster at the lower stand density in terms of the radial growth (DBH). This may be attributed to the wider tree spacing, which tends to favor the capture of sunlight, moisture and nutrients for tree growth and therefore accelerates growth rate [19]. This is also reflected in the larger crown size measured for the lower-density stand (Tab. I). In addition, a larger ST and a lower HD ratio were recorded at the lower stand density, indicating that the stem quality derived from this stand is comparatively inferior to those from higher stand densities in terms of the degree of stem taper.

There was no significant effect of stand density on wood basic density, which is an important wood quality attribute. This result was in accordance with previous findings for another fast-growing poplar clone in China [2]. However, Liu [17] reported that wood density decreased with increasing stand densities in Poplar 72 (Populus euramericana cv. I-72/58) and Poplar 69 (P. deltoids cv. I-69/55) growing on the beaches of the Changjiang River. This discrepancy may be attributed to differences in species and geographical location. According to the generalization made by Zobel and van Buijtenen [36], the initial stocking normally used in practice has little effect on wood density. Although exceptions to this generalization exist, our result was consistent with the generalization by Zobel and van Buijtenen. In addition, in comparison with other poplar clones in China, such as Populus deltoids, Nanlin-95 and Nanlin-447, this species has a relatively lower basic density $[5,9]$. This will be a disadvantage in utilization of the wood resources of this species since wood density 
is of key importance in forest product manufacture owing to its significance in determining both yield and quality of fibrous and solid wood products [36].

Fiber length is of importance for pulp and paper quality, and increased length is linked to better burst, tearing and tensile strength in paper [19]. This study indicated that fiber length was hardly influenced by stand density in Populus xiaohei. Similar results were obtained for other poplar clones such as Poplar 72 (Populus euramericana cv. I-72/58) and Poplar 69 (P. deltoids cv. I-69/55) [17], where fiber length was independent of tree spacing. As concluded by Zobel and van Buijtenen [36], a normal spacing variation has little effect on fiber length. However, the impact of stand density on fiber length is a confusing issue [30], and some contradictory results have been reported in other species. For example, it has been frequently observed for some coniferous species that wider spacings tend to produce shorter fibers $[11,26,30]$. These inconsistencies may be associated with differences in the genus studied, site conditions, climate and other environmental factors. The present study suggests that wider spacings may feasibly increase the rate of wood production while not affecting fiber length for pulpwood production in this species.

There were statistically significant differences in the mechanical characteristics of the wood between various stand densities. Tendencies towards positive relationships between stand density and both MOE and compression strength were observed, while the highest MOR was recorded at the moderate density of 500 stems/ha. Similar results were also reported for other species in terms of the effect of stand density on wood strength $[4,14,15]$. For example, a closerspaced stand yielded trees with a higher MOE in 11-year old Monterey pine (Pinus radiata D. Don) [14]. As suggested by Lasserre et al. [14], this may be related to reduced tree sway in denser stands because higher stand density tends to lower stem deflection by reducing wind speed within the canopy, which in turn results in an increase in wood stiffness [8]. In contrast, Zhang et al. [32] ascribed this finding to the fact that wide-spaced stands produce wood with larger knot sizes and hence inferior strength properties when compared with dense stands. These explanations may, to a certain degree, account for the variation in wood strength caused by various stand densities, since wood strength properties were found to be closely related to such wood characteristics as microfibril angle, latewood content, wood density and lignin content $[7,14]$. Therefore, further study should be carried out to explore the real cause of stand densityinduced variation in wood strength in Populus xiaohei.

Wet heartwood, characterized by anomalous moisture content in the heartwood part of the stem, tends to cause problems during wood drying by increasing drying time and producing defects $[12,13]$. In comparison with other poplar species in China such as Populus tomentosa [31] and Populus deltoides [35], Populus xiaohei contains a much higher proportion of wet heartwood, which may be explained by genetic differences. As suggested by Zhang et al. [31], the proportion of wet heartwood is greatly under genetic control. So far, there is no general agreement as to the cause and process of wet heartwood formation, and no reports in the literature regarding the impact of stand density on wet heartwood formation, $[12,38]$. This study indicated that there was a highly significant effect of stand density on HWA, and the lowest density resulted in noticeably higher HWP compared with the two higher densities. Our results suggest that the high HWP at low stand density may be partly attributable to high growth rate as indicated by DBH (Tab. I). In a similar study, Yang et al. [29] found that a wide spacing produced high percentage of heartwood in Picea mariana and Picea glauca.
As seen for wet heartwood, lower stand density resulted in larger JWA (Tab. II). A similar observation was also reported by Yang [28] in Picea glauca, where wide plantation spacing yielded more juvenile wood. According to the generalization made by Zobel and van Buijtenen [36], wider spaced plantations have trees with larger juvenile cores. This might be attributed to the fast growth rate resulting from wide spacing $[28,37]$. Correspondingly, the highest JWP was observed at the lowest stand density (Tab. II). A higher JWP at wider spacing was also reported by Yang [28] in Picea glauca. However, an opposite observation of decreasing JWP with increasing spacing was reported in Pinus elliottii [25]. These contradictory results suggest that the response of juvenile wood formation to stand density is species-specific. Compared with mature wood, juvenile wood characterized by shorter fiber, larger microfibril angle, lower wood density and strength etc., is inferior in wood quality, especially if it is from plantation trees [36].

\subsection{Relationships between tree characteristics and wood quality parameters}

The correlation analysis clearly demonstrated that there exist various degrees of correlation between tree characteristics and wood quality attributes in this species (Tab. III). Previous studies also indicated that there were relationships existing between wood quality parameters (e.g., MOE, MOR, sapwood basal area) and tree characteristics (e.g., crown width, DBH, tree height) $[1,15,27]$. Specifically, wood basic density was poorly related to any tree characteristics, which might be explained by the low variation in basic density between trees from various stand densities. It is interesting to note that fiber length was positively related to DBH. Usually, faster growing trees have shorter fibers [36]. However, mechanical properties were negatively correlated with most tree characteristics, indicating that fast growth rate resulted in lower mechanical properties. This is consistent with results obtained by Lei et al. [15] in black spruce (Picea mariana). As illustrated by Lasserre et al. [14], the reduced stiffness in larger trees could be attributed to the lower incidence of latewood in these trees since latewood fibers exhibit a higher stiffness than do those from earlywood. In this study, very poor correlation between the tree height and any wood quality characteristics was observed. Again, this might be due to the low variation in tree height among different stand densities (Tab. I).

Both JWA and HWA were highly correlated with most tree characteristics, especially with DBH (Tab. III). Since there is intrinsic relationships between tree and wood quality variables, some wood quality parameters may be predicted based on selected tree characteristics in this species.

\subsection{Modeling wood quality parameters in relation to tree characteristics}

The regression analysis showed that the selected tree characteristics, i.e. reciprocal of HD and DBH, could explain only $48 \%$ of total variation in MOE, and the reciprocal of HD contributed more to the prediction of MOE (Tab. IV). In a similar study, Lei et al. [15] found that ST was the best explanatory variable $\left(53 \%\right.$ of $\left.R^{2}=0.56\right)$ for the prediction of MOE in black spruce (Picea mariana), followed by other tree attributes. It should be emphasized that both HD and ST are important stem quality parameters. It should also be noted that 


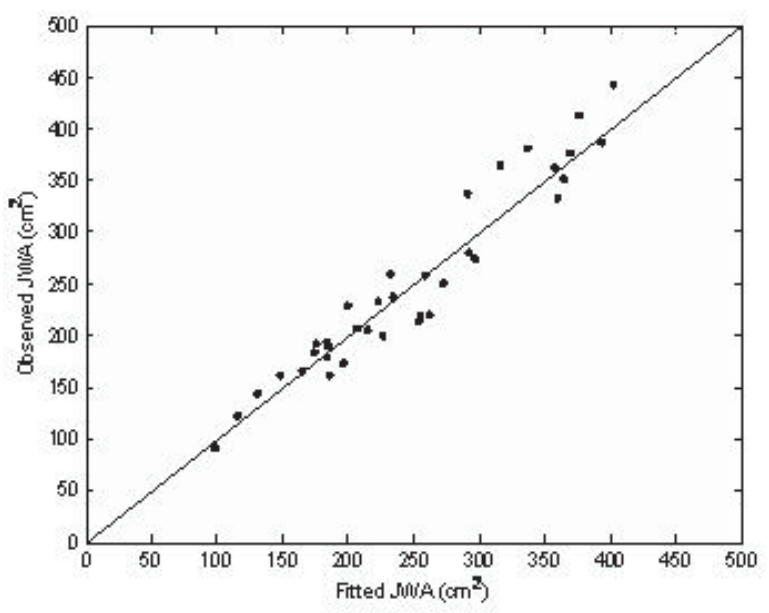

Figure 1. Observed juvenile wood basal area (JWA) versus predicted JWA in model $4\left(J W A=2.322 D B H^{1.741} S D^{-0.124}, n=36\right)$.

there was a high correlation between the explanatory variables, as indicated by the VIF value. For the predictions of MOR and compression strength, MOE was selected by the stepwise procedure in both models (models 2 and 3). In particular, MOE was the best explanatory variable for compression strength, accounting for $49 \%$ of the total variation. Previously, a significant and close relationship of MOE-MOR was discovered for many wood species $[6,15,24]$, and MOR can be best estimated from MOE and tree characteristics [3]. However, in this study MOE only explained $16 \%$ of the variation in MOR, which may partly be ascribed to the low sampling. In general, these models did not perform very well in describing the relationship of wood mechanical properties with tree characteristics, indicating that more effective explanatory variables should be incorporated into these models. As indicated by Castéra et al. [3], the effect of knots on wood strength is great, which may partly explain the relatively low $R^{2}$ value of MOR. In any case, these models provide an alternative method for prediction of wood strength from MOE and some tree characteristics, since MOE can be obtained by various nondestructive testing methods.

By contrast, JWA and HWA could be predicted very well based on selected tree characteristics, with $R^{2}$ values of 0.93 and 0.89 , respectively. The differences between the observed and fitted JWA and HWA are illustrated in Figures 1 and 2, respectively. For both models (models 4 and 5), DBH emerged as the best explanatory variable and could account for the majority of variation in both JWA and HWA, which was consistent with the results of correlation analysis (Tab. III). However, the models for basic density, fiber length, JWP and HWP performed poorly (Tab. IV). The failure in modeling basic density and fiber length in relation to tree characteristics may be due partly to the low variation in their values from different stand densities (Tab. II).

The stepwise analysis strongly indicated that tree characteristics such as DBH, HD and ST are important in determining wood quality. Consequently, some wood quality characteristics may be improved by altering tree growth traits (e.g. DBH). Although wood quality can be manipulated by genetic practices, environmental factors can also play an important role in determining wood quality [28]. Therefore, stand density can be manipulated in forest management to affect crown development and tree growth by changing growing conditions of trees, and eventually affect the wood quality produced.

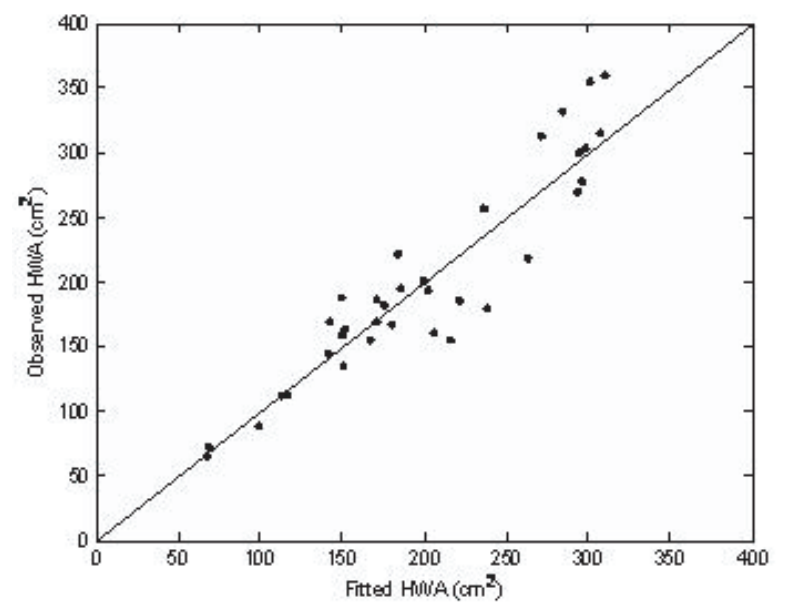

Figure 2. Observed wet heartwood basal area (HWA) versus predicted HWA in model 5 ( $H W A=0.674 D B H^{2.139} S T^{-0.477} S D^{-0.176}$, $n=36)$.

\section{CONCLUSIONS}

Populus xiaohei is one of the most important poplar species in Northern China. So far, there are no studies quantifying the effects of stand density on wood quality in this species. This study clearly indicated that there were significant effects of stand density on the radial growth of trees and crown size, and that lower stand density produced trees with larger stem taper.

There were no significant effects of stand density on either wood basic density or fiber length, while significant differences were found for wood mechanical properties between different stand densities. In addition, there were highly significant stand density effects on both JWA and HWA of individual trees, and the lower stand density was found to result in higher juvenile wood and wet heartwood content. Wood quality characteristics are best defined by the intended final products. Thus, stand density strategies should be aimed at the specific final products desired. For Populus xiaohei, a low-density strategy is feasible to maximize wood production while not decreasing fiber length or wood density for a pulpwood-oriented management purpose. However, if lumber production is targeted, a high density may be desirable to yield high-strength wood and reduce the production of juvenile wood and wet heartwood, despite being at the expense of increased establishment costs and reduced diameter growth of individual trees. Based on comprehensive consideration of various factors, such as wood quality, tree growth, and establishment cost, results from this study suggest that a density of $500 \mathrm{stems} / \mathrm{ha}$ is optimum for wood production.

The success in modeling some wood quality parameters (especially for JWA and HWA) in relation to tree characteristics indicates that information on wood quality in standing trees can be obtained before harvesting. However, it should be noted that these wood quality models have been established based on only 36 sample trees. Therefore, more sample trees should be harvested to validate and improve these models before they are applied in practice. Furthermore, as the occurrence of wet heartwood is severe in this species, information on its distribution inside the tree trunk and modeling its volume from easy-to-measure tree characteristics would provide a useful means for better understanding and controlling this phenomenon. In any case, it is clear that these models can potentially be applied to predict some 
wood quality parameters based on tree characteristics which are routinely recorded in forest inventory.

Acknowledgements: This study was supported by the National Natural Science Foundation of China. The authors are grateful to Mingkun $\mathrm{Xu}$, Heying $\mathrm{Wu}$, Xiuqin Luo, and Qun Zhang from the Chinese Academy of Forestry, who provided support during field and laboratory work. We also thank Dr. Tony Zhang of Forintek Canada Corp. for his assistance in experimental design and paper writing. Thanks are also extended to Mr. Jack Gates and Mr. Ben Bryant for revising the language of this manuscript.

\section{REFERENCES}

[1] Amarasekara H., Denne M.P., Effects of crown size on wood characteristics of Corsican pine in relation to definitions of juvenile wood, crown formed wood and core wood, Forestry 75 (2002) 51-61.

[2] Bao F.C., Jiang Z.H., Wood properties of main tree species from plantation in China, China Forestry Publishing House, Beijing, China, 1998.

[3] Castéra P., Faye C., Ouadrani A.E., Prevision of the bending strength of timber with a multivariate statistical approach, Ann. For. Sci. 53 (1996) 885-898.

[4] Chuang S.T., Wang S.Y., Evaluation of standing tree quality of Japanese cedar grown with different spacing using stress-wave and ultrasonic-wave methods, J. Wood Sci. 47 (2001) 245-253.

[5] Fang S.Z., Yang W.Z., Within tree variation in wood basic density and cellulose content of poplar clones, J. Plant Res. Environ. 13 (2004) 19-23.

[6] Faust T.D., McAlister R.H., Zarnoch S.J., Strength and stiffness properties of sweetgum and yellow-poplar structural lumber, For. Prod. J. 40 (1991) 58-64.

[7] Gindl W., Teischinger A., Axial compression strength of Norway spruce related to structural variability and lignin content, Compos. Part A. Appl. Sci. Manuf. 33 (2002) 1623-1628.

[8] Green S.R., Grace J., Hutchings N.J., Observation of turbulent air flow in three stands of widely spaced Sitka spruce, Agric. For. Meteorol. 74 (1995) 205-225.

[9] Jiang X.M., Zhang L.F., Zhang Q.W., Genetic variation in basic wood properties of 36 clones of Populus deltoides, For. Res. 7 (1994) 253-258.

[10] Jiang Z.H., Peng Z.H., Wood properties of the global important tree species, Science Press, China, 2001.

[11] Kang K.Y., Zhang S.Y., Mansfield S.D., The effects of initial spacing on wood density, fiber and pulp properties in jack pine (Pinus banksiana Lamb.), Holzforschung 58 (2004) 455-463.

[12] Krause C., Gagnon R., Wet heartwood distribution in the stem, stump, and root wood of black spruce in the Quebec boreal forest, Canada, North. J. Appl. For. 22 (2005) 12-18.

[13] Krause C., Gagnon R., The relationship between site and tree characteristics and the presence of wet heartwood in black spruce in the boreal forest of Quebec, Canada, Can. J. For. Res. 36 (2006) 15191526.

[14] Lasserre J.P., Mason E.G., Watt M.S., The effects of genotype and spacing on Pinus radiata (D. Don) corewood stiffness in an 11-year old experiment, For. Ecol. Manage. 205 (2005) 375-383.

[15] Lei Y.C., Zhang S.Y., Jiang Z.H., Models for predicting lumber bending MOR and MOE based on tree and stand characteristics in black spruce, Wood Sci. Technol. 39 (2005) 37-47.

[16] Li S.W., Zhang Z.Y., He C.Z., An X.M., Progress on hybridization breeding of poplar in China, World For. Res. 17 (2004) 37-41.

[17] Liu S.Q., Effect of different spaces on wood quality in poplar, J. Anhui Agric. Univ. 27 (2000) 374-379.
[18] Lu J.X., Bao F.C., Plantation in the future in China: forest silviculture, wood quality and utilization, Forest. Stud. China, 2 (1999) $16-23$.

[19] Macdonald E., Hubert J., A review of the effects of silviculture on timber quality of Sitka spruce, Forestry 75 (2002) 107-138.

[20] Mmolotsi R.M., Teklehaimanot Z., The effect of initial tree-planting density on timber and wood-fuel properties of red alder and sycamore, Can. J. For. Res. 36 (2006) 1475-1483.

[21] National Technical Monitoring Bureau, National standard GB 1932 1942-91: Standard methods for determining wood physical and mechanical properties, China Standard Press, Beijing, 1991.

[22] Persson B., Persson A., Stahl E.G., Karlmats U., Wood quality of Pinus sylevstris progenies at various spacing, For. Ecol. Manage. 76 (1995) 127-138.

[23] Ren H.Q., Liu X.E., Jiang Z.H., Wang Y.H., Yu H.Q., Effects of planting density on wood anatomical properties of Populus xiaohei, For. Res. 19 (2006) 364-369.

[24] Roos K.D., Shottafer J.E., Shepard R.K., The relationship between selected mechanical properties and age in quaking aspen, For. Prod. J. 40 (1990) 54-56.

[25] Saucier J.R., Forest management and wood quality, in: Saucier J.R., Cubbage F.N. (Eds.), Proceedings, Southern Plantation Wood Quality Workshop, Athens, GA, 1990, pp.47-56.

[26] Watson P., Garner C., Robertson R., Reath S., Gee W., Hunt K., The effects of initial tree spacing on the fiber properties of plantationgrown coastal western hemlock, Can. J. For. Res. 33 (2003) 24602468.

[27] Whitehead D., Edwards W.R.N., Jarvis P.G., Conducting sapwood area, foliage area, and permeability in mature trees of Picea sitchensis and Pinus contorta, Can. J. For. Res.14 (1984) 940-947.

[28] Yang K.C., Impact of spacing on width and basal area of juvenile and mature wood in Picea mariana and Pieca glauca, Wood Fiber Sci. 26 (1994) 479-488.

[29] Yang K.C., Hazenberg G., Impact of spacing on sapwood and heartwood thickness in Picea mariana (Mill.) B.S.P. and Pieca glauca (Moench.) VOSS, Wood Fiber Sci. 24 (1992) 330-336.

[30] Yang K.C., Hazenberg G., Impact of spacing on tracheid length, relative density, and growth rate of juvenile wood and mature wood in Picea mariana, Can. J. For. Res. 24 (1994) 996-1007.

[31] Zhang D.M., Bao F.C., Zhang Z.Y., Huang R.F., Genetic analysis of wetwood proportion on clone test stand of Populus tomentosa, Sci. Sil. Sin. 41 (2005) 140-144.

[32] Zhang S.Y., Chauret G., Ren H.Q., Desjardins R., Impact of plantation black spruce initial spacing on lumber grade yield, bending properties and MSR yield, Wood Fiber Sci. 34 (2002) 460-475.

[33] Zhang S.Y., Lei Y.C., Bowling C., Quantifying stem quality characteristics in relation to initial spacing and modeling their relationship with tree characteristics in black spruce (Picea mariana), North. J. Appl. For. 22 (2005) 85-93.

[34] Zhang S.Y., Tong Q.J., Modeling lumber recovery in relation to selected tree characteristics in jack pine using sawing simulator Optitek, Ann. For. Sci. 62 (2005) 219-228.

[35] Zhu G.Q., Huang M.R., Pan H.X., Li H.G., Feng W.Z., Study on chemical characteristics and formation mechanism of poplar wet heartwood, Sci. Sil. Sin. 33 (1997) 260-266.

[36] Zobel B.J., Buijtenen J.P., Wood variation-its cause and control, Springer-verlag, Berlin, Heidelberg, New York, London, Paris, Tokyo, 1989.

[37] Zobel B.J., Webb C., Henson F., Core or juvenile wood of loblolly and slash pine trees, TAPPI 42 (1959) 345-356.

[38] Zu B.S., Foreign studies on wet heart wood of poplars, Sci. Sil. Sin. 36 (2000) 85-91. 